CARTA AL EDITOR

\section{RÉPLICA: LAS PRUEBAS DE LABORATORIO PARA LA IDENTIFICACIÓN DE SARS-COV-2 EN TIEMPOS DE PANDEMIA EN EL PERÚ: ALGUNAS PRECISIONES ACERCA DEL «RENDIMIENTO DIAGNÓSTICO»}

\section{REPLY: LABORATORY TESTS FOR IDENTIFICATION OF SARS-COV-2 DURING PANDEMIC TIMES IN PERU: SOME CLARIFICATION REGARDING «DIAGNOSTIC PERFORMANCE»}

\author{
Margot Vidal-Anzardo (1) 1,a, Gilmer Solis (102, \\ Lely Solari ${ }^{1, a, c}$, Gabriela Minaya $\mathbb{1}^{2, a, d}$, \\ Beatriz Ayala-Quintanilla (2),a,e Jonh Astete-Cornejo (1),a,f, \\ Amparo Luque-Aguilar (10,a,g, Ana Jorge (i) 4,

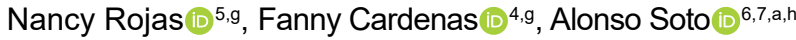 \\ 1 Centro Nacional de Salud Pública, Instituto Nacional de Salud, Lima, Perú. \\ 2 Oficina General de Investigación y Transferencia Tecnológica, Instituto \\ Nacional de Salud, Lima, Perú. \\ 3 Centro Nacional de Salud Ocupacional y Protección del Ambiente para la \\ Salud, Lima, Perú. \\ 4 Laboratorio de Referencia Nacional de Bacterias de Transmisión Sexual, \\ Instituto Nacional de Salud, Lima, Perú. \\ 5 Laboratorio de Referencia Nacional de Virus Respiratorio, Instituto Nacional \\ de Salud, Lima, Perú. \\ 6 Instituto de Investigación en Ciencias Biomédicas, Facultad de Medicina \\ Humana, Universidad Ricardo Palma, Lima, Perú. \\ Departamento de Medicina, Hospital Nacional Hipólito Unanue, Lima, Perú. \\ a Médica/o cirujana/o; ${ }^{\text {b }}$ cirujano dentista; ${ }^{\mathrm{c}}$ especialista en Infectología, doctora \\ en Ciencias de Salud; ${ }^{d}$ especialista en Infectología, magíster en Salud Pública \\ y Bioética; ${ }^{\mathrm{e}}$ especialista en Ginecología y Obstetricia, doctora en Medicina; \\ ${ }_{\mathrm{f}}$ especialista en Medicina Ocupacional y del Medio Ambiente, magíster en \\ Administración de Empresas con especialidad en Gestión Integrada de la \\ Calidad, Seguridad y Medio Ambiente; ${ }^{\mathrm{g}}$ bióloga; ${ }^{\mathrm{h}}$ especialista en medicina \\ interna y doctor en Ciencias Médicas.
}

Sr. Editor: Hemos recibido la carta «Las pruebas de laboratorio para la identificación de SARS-CoV-2 en tiempos de pandemia en el Perú: Algunas precisiones acerca del "rendimiento diagnóstico"» de Maguiña et al. y deseamos expresar nuestro agradecimiento a los autores por la ampliación bibliográfica, así como por sus cálculos adicionales. Antes de resolver las dudas planteadas, quisiéramos contextualizar el estudio, el cual se planificó y ejecutó cuando llegaron al país las pruebas serológicas (PS) o también llamadas pruebas rápidas, cuya utilidad debía

\footnotetext{
Citar como: Vidal-Anzardo M, Solis G, Solari L, Minaya G, Ayala-Quintanilla B, Astete-Cornejo J, et al. Réplica: Las pruebas de laboratorio para la identificación de SARS-CoV-2 en tiempos de pandemia en el Perú: Algunas precisiones acerca del «rendimiento diagnóstico». Rev Peru Med Exp Salud Publica. 2020;37(3):577-9. doi: https://doi.org/10.17843/rpmesp.2020.373.5929.
}

Correspondencia: Margot Haydée Vidal Anzardo; Cápac Yupanqui 1400, Jesús María, Lima, Perú; mvidal@ins.gob.pe

Recibido: 03/06/2020 Aprobado: 03/06/2020 En línea: 18/08/2020 ser evaluada prontamente a fin de obtener evidencia de su utilidad para diagnosticar la COVID-19 en el país. Dicho esto, el estudio se ejecutó en solo dos días; por lo que reconocemos que es factible que haya errores, debido a ello recurrimos a la capacidad de evaluación crítica de todos los lectores para su correcta interpretación.

En cuanto a las tres observaciones planteadas, identificamos que Maguiña et al. expresan la existencia de ambigüedad ante el término «rendimiento diagnóstico», pero creemos que esto se debe a una inadecuada interpretación, ya que como se observa en nuestro artículo el término usado es «rendimiento diagnóstico adicional», el cual es un aspecto claramente diferente, siendo éste un término numérico que expresa la cantidad de resultados positivos obtenidos por un test determinado de entre todos los positivos obtenidos por las pruebas realizadas ${ }^{(1)}$. Dicho indicador fue establecido para obtener una valoración rápida en condiciones de campo en las que se contaba con los resultados de ambas pruebas. Reconocemos las limitaciones metodológicas y de interpretación que pudieran tener estas ante circunstancias diferentes, algo que sucede habitualmente en muchas investigaciones. A fin de transparentar la información, decidimos colocar las tablas con la distribución de los datos encontrados para que los lectores puedan evaluarlos según los criterios que consideren adecuados a sus realidades. Los autores que plantean la observación que da origen a esta réplica establecen una interesante alternativa de cálculo; sin embargo, no consideramos adecuado asumir, como ellos, que una sea «más apropiada» que otra, aunque agradecemos la sugerencia y saludamos su esfuerzo. Dicho esto, creemos que podrían haberlo manejado como un subanálisis en un artículo breve propio.

El segundo problema que identifican Maguiña et al. recae en la valoración de la sensibilidad y especificidad. Al respecto hacemos hincapié en la información consignada en el sexto párrafo de la discusión de nuestro artículo, donde textualmente expresamos: «adicionalmente, debemos señalar que nuestros estimados de sensibilidad y especificidad representan datos preliminares y que deben corroborarse en estudios de mayor tamaño muestral» (2). Asimismo, enfatizamos nuestro desacuerdo en querer emplear los datos que hemos presentado para realizar dichos cálculos, ya que nuestro estudio no fue diseñado para dicho fin, y el tamaño de muestra es insuficiente para obtener estimadores confiables de dichas valoraciones ${ }^{(3)}$.

Aprovechamos la oportunidad para recordar a los lectores que si bien, matemáticamente se pueden hacer muchos cálculos de rendimiento diagnóstico o de concordancia, estos deben basarse en fundamentos metodológicos (diseño y tamaño de muestra), y que Maguiña et al. lo señalan en el cuarto párrafo de su carta: «un inadecuado tamaño de muestra produce estimaciones imprecisas que resultan poco útiles». Caso contrario, se haría uso irresponsable e inadecuado de la evidencia, hecho por el cual lo descartamos durante el estudio, aunque se decidió dejar algunos cálculos bajo la de- 
Tabla 1. Réplica de los autores a las observaciones planteadas con QUADAS-2 (Quality Assessment of Diagnostic Accuracy Studies)

\begin{tabular}{|c|c|c|}
\hline Dominios y resumen de preguntas & Resultado & Justificación del resultado según Maguiña et al. \\
\hline \multicolumn{3}{|l|}{$\begin{array}{l}\text { Selección de pacientes } \\
\text { ¿Podría la selección de pacientes haber } \\
\text { introducido sesgos? }\end{array}$} \\
\hline Muestra consecutiva o aleatoria & Incierto & $\begin{array}{l}\text { Se indica en el estudio que tres grupos con diferentes } \\
\text { condiciones fueron analizados, pero no se explica } \\
\text { si el reclutamiento fue aleatorio, consecutivo, o por } \\
\text { conveniencia. }\end{array}$ \\
\hline Evitó casos y controles & Bajo & No se usó un diseño caso-control. \\
\hline Evitó exclusiones inapropiadas & Incierto & $\begin{array}{l}\text { El estudio no reporta cuáles fueron sus criterios de } \\
\text { exclusión ni si algunos pacientes fueron excluidos. }\end{array}$ \\
\hline
\end{tabular}

\section{Prueba índice (PI)}

¿Podría la realización o la interpretación de

la prueba índice haber introducido sesgos?

Cegamiento de prueba de referencia

Umbral especificado de $+\mathrm{o}$ - antes del estudio

No aplica

Prueba de referencia (PR)

¿Podría la realización o la interpretación de la prueba de referencia haber introducido sesgos?

Estándar de oro adecuado (definición estandarizada)

Cegamiento de prueba índice

Incierto

No se detalla en el artículo si el personal que inter-

El estándar de referencia usado fue el RT-PCR de muestras respiratorias; sin embargo, en condiciones de campo puede no ser ideal debido a problemas en la toma de muestra y transporte. Entendemos que la idea era evaluar y comparar tanto el RT-PCR como la prueba serológica en condiciones reales, para lo cual hubiera sido preferible comparar ambas pruebas contra un estándar confiable.

pretó la prueba de referencia conocía o desconocía el resultado de la prueba índice.
En las últimas líneas del quinto párrafo de materiales y métodos se lee «El tipo de muestreo empleado fue no probabilístico por conveniencia", pero ante la duda señalamos que el reclutamiento fue por conveniencia, debido al contexto en el que se ejecutó el estudio.

Efectivamente no fue un diseño caso-control.

Se excluyeron a menores de edad y pacientes en UCI, debido a las complicaciones inherentes a las autorizaciones éticas.

El personal que ejecutó la prueba serológica desconocía el resultado de la RT-PCR, dado que los resultados se generan en tiempos diferentes. Cabe precisarse que no todos los pacientes hospitalizados tenían un resultado de RT-PCR al momento de la evaluación.

No aplica.

Se debe considerar que para la fecha de ejecución del estudio, en el Perú solo se contaba con la RT-PCR como método auxiliar de diagnóstico, y resaltar que el cuadro clínico es poco útil para casos asintomáticos y leves.

El personal que ejecutó la prueba serológica desconocía el resultado de la RT-PCR, dado que los resultados se generan en tiempos diferentes. Cabe precisarse que no todos los pacientes hospitalizados tenían un resultado de RT-PCR al momento de la evaluación.

\section{Flujo y tiempos \\ ¿Podría el flujo de pacientes haber introducido sesgos?}

Aún no está definida adecuadamente la respuesta inmunológica al virus SARS-CoV-2 ni la velocidad de aclaramiento del virus, por lo que el intervalo de tiempo entre la toma de una prueba molecular y una prueba serológica podría afectar los resultados llevando a sesgo. El tiempo entre pruebas es importante pero no fue reportado.

Todos los sujetos fueron evaluados por ambas pruebas.

Si bien existen dos grupos de evaluación: 1) sujetos con datos completos para fecha de inicio de síntomas $(\mathrm{n}=109)$ y 2$)$ total de la muestra $(\mathrm{n}=234)$ que incluye los sueros provenientes de la seroteca; se consideró que cada subgrupo fue analizado en forma completa.
La muestra obtenida por RT-PCR y prueba rápida fue simultánea en la mayoría de casos. Solo en algunos casos de pacientes hospitalizados se tardó días antes la toma de muestra para RT-PCR, pero como señalamos en el cuarto párrafo de materiales y métodos, no se pudo repetir la evaluación por consideraciones éticas. Sesgo que asumimos.

Efectivamente, se aplicaron ambas pruebas a los sujetos.

Efectivamente, se evalúo considerando la falta de datos. 
nominación de «datos preliminares», los que, exhortamos, deben interpretarse bajo esa lógica. Recomendamos a los autores de la carta realizar un estudio propio con un diseño específico de validación y con un tamaño de muestra adecuado ${ }^{(4)}$, en el que puedan usar los conocimientos exhibidos en sus observaciones, las cuales, consideramos, no van acorde a lo planteado en nuestro estudio.

En consideración a la tercera observación presentada sobre la valoración del riesgo de sesgo, la creemos sumamente interesante, aunque muchas de las justificaciones a los resultados señalados por Maguiña et al. ameritan ser aclaradas. Nosotros expresamos nuestra réplica a ellas en la Tabla 1 y consideramos poco adecuado desmerecer las limitaciones que aporta el contexto de la emergencia sanitaria a nuestro estudio. Nos preocupa advertir que Maguiña et al. malinterpretaron el contenido del artículo, ya que manifiestan que «hubo preocupantes niveles de riesgo de sesgo y problemas de aplicabilidad de los resultados como para recomendar su uso en lugar de las pruebas moleculares». Queremos aclarar que en ningún momento hemos recomendado usar las pruebas rápidas en reemplazo de las moleculares, es más, aprovechamos esta réplica para manifestar que las pruebas rápidas son útiles por complementar a las moleculares.

Finalmente, esperamos que se realicen nuevos estudios, bajo diseños que determinen la validez diagnóstica y la concordancia de las pruebas rápidas en escenarios ideales.

Contribuciones de autoría: Todos los autores participaron en la concepción, redacción, revisión final y aprobación del manuscrito. Asimismo, asumen la responsabilidad por sus contenidos.
Fuentes de financiamiento: La investigación que motivó la réplica a la carta al editor fue financiada a través del Centro Nacional de Salud Pública del Instituto Nacional de Salud del Perú.

Conflictos de interés: Todos los autores a excepción de Alonso Soto son trabajadores del Instituto Nacional de Salud. Margot Vidal Anzardo es directora ejecutiva de la Dirección Ejecutiva de Enfermedades No Transmisibles/Centro Nacional de Salud Pública. Lely Solari es directora general del Centro Nacional de Salud Pública y miembro del Comité Editor de la Revista Peruana de Medicina Experimental y Salud Pública. Jonh Astete Cornejo es director ejecutivo de la Dirección de Medicina y Psicología del Trabajo/Centro Nacional de Salud Ocupacional y Protección del Medio Ambiente para la Salud. Ana Jorge es coordinadora del Laboratorio de Referencia Nacional de Bacterias de Transmisión Sexual. Nancy Rojas es coordinadora de Laboratorio de Virus Respiratorios. Fanny Cárdenas es coordinadora del Laboratorio de Virus de Transmisión Sexual y VIH/ SIDA. Alonso Soto es miembro del Comité Editor de la Revista Peruana de Medicina Experimental y Salud Pública.

\section{REFERENCIAS BIBLIOGRÁFICAS}

1. Tello G, Ugarte M, Agapito J, Soto A. Detección de tuberculosis en el servicio de emergencia: utilidad de la segunda baciloscopía realizada el mismo día. Rev Peru Med Exp Salud Publica. 2012;29(2):223-227. doi: 10.17843/rpmesp.2012.292.345.

2. Vidal-anzardo M, Solis G, Solari L, Minaya G, Ayala-quintanilla B, Astete-cornejo J, et al. Evaluación en condiciones de campo de una prueba serológica rápida para detección de anticuerpos IgM e IgG contra SARSCoV-2. Rev Peru Med Exp Salud Publica. 2020;37(2). doi: 10.17843/ rpmesp.2020.372.5534.

3. Liu XS. Comparing sample size requirements for significance tests and confidence intervals. Counseling outcome research and evaluation. 2013;4(1):3-12. doi: 10.1177/2150137812472194.

4. Arafat SMY. Validation study can be a separate study design. Int J Med Sci Public Health. 2015;5(11). doi: 10.5455/ijmsph.2016.19042016471. 